\title{
TIPOLOGIA DE CONSTRUÇÕES CLIVADAS DE UM CORPUS DE LÍNGUA ORAL ESPONTÂNEA
}

\author{
TYPOLOGY OF CLEFT CONSTRUCTIONS OF AN ORAL SPONTANEOUS SPEECH \\ CORPUS
}

Submetido em: 04-04-2012

Publicado em: 23-02- 2013

Luis Filipe Lima e Silva ${ }^{1}$ luisf.1397@gmail.com

Resumo: As construções clivadas são estudadas sob três grandes abordagens: a gerativa, a de teste induzido ou de leitura e a de língua oral espontânea. Este trabalho tem por objetivo explicitar a tipologia dessas construções a partir de um corpus de língua oral espontânea. Os resultados da pesquisa apontam que o fenômeno da clivagem na língua oral espontânea se difere, em alguns aspectos, dos dados de introspecção e das descrições prévias das tipologias prosódicas apontadas pelos testes de leitura. Foram encontradas construções clivadas prototípicas, invertidas, com dupla cópula, sem cópula e interrogativas. Constatou-se, também, que nem sempre o pitch accent se encontra na parte não-pressuposta dessas construções.

Palavras-chave: Construções Clivadas. Foco. Prosódia. Português Brasileiro.

Abstract: Cleft constructions are studied under three broad approaches: generative, induced test or reading test and spontaneous speech. The objective of this article is to describe the typology of these constructions based on a spontaneous Brazilian Portuguese speech corpus. The results of this research show that clefting in spontaneous speech differs in some respects from introspective data analysis as well as from the previous descriptions of prosodic typologies induced by reading tests. The findings revealed besides prototypic cleft constructions, inverted, double copula, copula-less and interrogative constructions. It was also found that the pitch accent is not always in the non-presupposed part of these constructions.

Keywords: Cleft Constructions. Focus. Prosody. Brazilian Portuguese.

\section{INTRODUÇÃO}

Há três grandes correntes de estudos sobre as construções clivadas: os de abordagem gerativa, os de testes induzidos ou de leitura e os de fala espontânea ${ }^{2}$. Os trabalhos de abordagem gerativa têm representado grande parte dos estudos dedicados às construções clivadas. Dentro dessa perspectiva teórica, essas construções têm sido exploradas a partir de seu aspecto formal, norteado por relações de pressuposição de

\footnotetext{
${ }^{1}$ Graduando do curso de Letras (habilitação em Linguística) da UFMG. Este trabalho foi orientado pela Prof $^{\mathrm{a}}$. Heliana Mello e financiado pela FAPEMIG.

${ }^{2}$ Entendemos como corrente de estudo um mesmo segmento que adota certa metodologia e se apóia em determinada teoria. A abordagem gerativa guia sua metodologia por pressupostos teóricos próprios, analisando dados de introspecção, já a abordagem de testes de leitura se guia pelos pressupostos da teoria gerativa, porém possui outra metodologia de análise, baseada coleta de dados orais induzidos, e, por fim, a abordagem de fala espontânea se guia por pressupostos funcionalistas e possui ainda outra metodologia, baseada em coleta de dados orais espontâneos. Vale salientar que assumimos essa posição tomando por base estudos prévios a que tivemos acesso, citados neste artigo.
}

Work. pap. linguíst., 13(3): 45-61, Florianópolis, out.dez,2012 
base lógica e de propriedades semânticas do foco (cf. KRUG DE ASSIS, 2001; MODESTO, 2001; RESENES, 2009). Esses estudos buscam descrever a sintaxe das construções clivadas, os movimentos do(s) constituinte(s) focalizado(s) e delimitar as características que fazem uma construção ser clivada. Os estudos de testes induzidos ou de leitura levam em consideração as descrições da abordagem gerativa, contudo buscam propor uma tipologia prosódica dessas construções, mostrando a relação do foco com a curva de pitch a partir da leitura ou da produção de uma sentença dentro de um contexto fornecido (cf. ARAÚJO, 2010; FERNANDES-SVARTMAN, 2007). Os estudos de fala espontânea buscam elucidar questões pragmático-discursivas, partindo do contexto em que a sentença foi enunciada e o papel que ela desempenha na conversação sendo parte do fenômeno da focalização (cf. BRAGA; BARBOSA, 2009). Geralmente, esses estudos se apóiam em pressupostos funcionalistas.

Tendo em vista que pouca atenção tem sido dada à descrição das construções clivadas usando como suporte um corpus de fala espontânea, o objetivo deste trabalho é descrever a tipologia dessas construções partindo de um corpus de língua oral espontânea chamado C-ORAL-BRASIL (RASO; MELLO, 2012).

\section{ASPECTOS TEÓRICOS}

\subsection{Focalização e foco}

A clivagem é um processo sintático que faz parte de um fenômeno linguístico mais amplo chamado focalização. Isso significa que uma construção clivada é designada para focalizar. A focalização é um fenômeno que tem por objetivo realçar partes do enunciado. Nas diversas línguas do mundo, esse realce, também conhecido como foco, pode se dar por meio da fonologia, da sintaxe ou ainda da morfologia. $\mathrm{O}$ foco apresenta propriedades semântico-pragmáticas e prosódicas. Essas propriedades são expressas, sobretudo, pela relação de pressuposição e de proeminência prosódica ou pitch accent. A propriedade de pressuposição do foco está relacionada ao extenso debate na literatura sobre informação dada/nova, tema/rema, tópico/comentário, etc. (cf. BARBOSA, 2005). Nas palavras de Gonçalves, o constituinte focalizado é "a parcela do texto apresentada como a mais informativa/relevante" (GONÇALVES, 1998, p. 32). O autor diz que "a focalização constitui, por sua própria natureza de 'realçar elementos do enunciado', informação new" (GONÇALVES, 1998, p. 33). Os elementos fora de foco, como menciona o autor, "constituem informação apresentada previamente" (GONÇALVES, 1998, p. 32), ou seja, a informação dada. Contudo, o autor adverte que a informação nova não diz respeito ao que não foi mencionado previamente no discurso, mas é nova porque "o falante tende a interpretar como não-suscetível de recuperação (a) nem a partir do texto precedente (co-texto); e (b) nem por meio do contexto pragmático (situacional imediato)" (GONÇALVES, 1998, p. 33). Outra propriedade do foco é a elevação da frequência fundamental ou F0. Com isso, o constituinte focalizado alcança o pico acentual ou pitch accent. Outras estratégias prosódicas como duração e intensidade também servem para dar realce a algum elemento do enunciado, fazendo assim parte da estratégia prosódica do fenômeno da focalização.

Encontram-se três tipos de foco atestados na literatura, a saber, o foco de informação, o foco contrastivo e o foco de identificação. Esses focos ocorrem de acordo com o contexto da sentença. As propriedades desses três tipos de foco seriam expressas por traços definidores de contraste e de exaustividade. Zubizarreta (1998) cita o foco 
contrastivo e o não-contrastivo ${ }^{3}$. Esses focos estariam explicitados em um nível pragmático chamado Estrutura de Asserção (AS), em que se dá a focalização, a pressuposição e os focos. Resenes explica que "o foco não-contrastivo presume uma pergunta wh como base discursiva para ser estabelecido" (RESENES, 2009, p. 20). Esse foco expressa uma informação não-pressuposta. A autora fornece o seguinte exemplo ${ }^{4}$ :

(1) a. $O$ que o João bebeu?

b. O João bebeu alguma coisa.

c. O João bebeu [F o vinho].

A pergunta wh está em (1a). Em (1b), encontra-se a pressuposição expressa pelo pronome indefinido. $O$ foco não-contrastivo se encontra em (1c) e é o valor da expressão wh da pergunta em (1a). O foco contrastivo é aquele que tem por função corrigir uma afirmação prévia. Resenes $(2009$, p. 21) cita o exemplo5:

(2) a. O João bebeu o vinho.

b. O João bebeu [F a cerveja]. (não o vinho)

Kiss (1998) classifica o foco por traços [-exaustivo] e [+exaustivo]. O foco de informação receberia o traço [-exaustivo] e o foco de identificação receberia o traço [+exaustivo]. O exemplo prototípico de aplicação do foco de identificação é justamente uma sentença clivada. Considerando o seguinte exemplo ${ }^{6}$ de Resenes (2009, p. 21):

(3) Foi [F um perfume] que a Maria deu para o João.

Em (3), o foco de identificação é expresso pelo NP um perfume, que significa que dentro de uma série de possíveis presentes que a Maria poderia ter dado ao João, ela deu somente um perfume. Por isso, "a exaustividade é lida como $x$ e apenas $x$ " (RESENES, 2009, p. 22). Mioto (2003, p. 175 apud RESENES, 2009, p. 22) ${ }^{7}$ mostra um quadro com os tipos de foco propostos por Zubizaretta (1998) e Kiss (1998):

(4)

\begin{tabular}{|l|l|}
\hline a. $[$-contrastivo, -exaustivo] & de informação $(\mathrm{K})$, não-contrastivo $(\mathrm{Z})$ \\
\hline b. $[$-contrastivo, + exaustivo] & de identificação $(\mathrm{K})$ \\
\hline c. $[$ +contrastivo, -exaustivo] & $* 8$ \\
\hline d. $[$ +contrastivo, + exaustivo] & contrastivo $(\mathrm{Z})$ e $(\mathrm{K})$ \\
\hline
\end{tabular}

Quadro 1 - Tipos de foco segundo traços definidores

Resenes cita ainda outro tipo de foco. O foco apresentativo "é um foco que introduz um elemento novo no universo do discurso, como em início de narrativas" (RESENES, 2009, p. 22). A autora cita os seguintes exemplos ${ }^{9}$ :

\footnotetext{
${ }^{3}$ O foco não-contrastivo citado por Zubizarreta (1998) corresponde ao foco de informação mencionado na literatura.

${ }^{4}$ Exemplo (8) no original.

${ }^{5}$ Exemplo (10) no original.

${ }^{6}$ Exemplo (12) no original.

${ }^{7}$ Quadro (14) de Resenes (2009, p. 22). As iniciais (Z) e (K) indicam Zubizarreta e Kiss.

${ }^{8}$ Resenes (2009, p. 22) menciona que “o foco contrastivo já engloba o traço exaustivo", por isso o traço [exaustivo] fica anulado.

${ }^{9}$ Exemplo (15) no original.
}

Work. pap. linguíst., 13(3): 45-61, Florianópolis, out.dez,2012 
(5) a. Era uma vez um príncipe.

b. Vivia numa floresta uma princesa muito bonita.

c. Apareceu na cidade um circo.

Resenes explica que esse foco "é veiculado por uma sentença inteira sem que essa sentença seja constituinte de outra, isto é, a sentença propriamente não expressa a pressuposição" (RESENES, 2009, p. 22). De acordo com a forma, esse foco é também chamado de foco largo, visto que os tipos de foco mostrados anteriormente são chamados de foco estreito.

\subsection{Clivagem}

Entre descrições mais e menos refinadas, a literatura sobre o tema, de modo geral, aponta uma construção clivada como uma estrutura sintática complexa em que uma oração simples é dividida em duas, com a presença de uma cópula e de um elemento focalizado. O objetivo de uma construção clivada é colocar um elemento do enunciado em evidência ou como foco. Para isso, o elemento que se pretende colocar em evidência é expresso dentro de uma oração principal, precedida de uma cópula, seguida do complementizador que e de uma oração subordinada. Na terminologia gerativista, a estrutura de uma sentença clivada é: $\mathrm{ser}+\mathrm{XP}+$ que $+\mathrm{IP}$, por exemplo, [IP foi [DP o kiwii [CP que [IP o Pedro comeu eci]]]]. Contudo, não basta uma sentença apresentar essa estrutura para ser uma clivada. A literatura gerativista afirma que é necessário haver uma categoria vazia no IP encaixado, pois ela retomaria a interpretação do constituinte pós-cópula como foco. Resenes explica que "a função discursiva do XP pós-cópula é crucial para que a sentença seja uma clivada - se ele não for o foco, definitivamente, a sentença não é uma clivada" (RESENES, 2009, p. 26). O foco necessita ser a parte nãopressuposta da sentença. Na língua oral espontânea a relação de pressuposição é construída pragmaticamente, o que torna mais difícil sua representação por meio de algoritmos, como são, geralmente, vistos nos dados de introspecção ${ }^{10}$. Pode ocorrer que o foco preceda a cópula, neste caso, a estrutura sintática recebe o nome de clivada invertida, apresentando a seguinte sequência: XP + ser + que + IP.

Modesto define uma construção clivada como "sentenças especificacionais em que um movimento A-barra dispara leituras características de contraste, exclusividade e exaustividade" (MODESTO, 2001, p. 21). O foco de uma clivada ocupar uma posição A-barra ${ }^{11}$ é uma das explicações de que a oração subordinada em uma clivada não é uma relativa livre, como muitos autores descrevem, pois

suas funções gramaticais têm que ser estabelecidas dentro da sentença encaixada, contrariamente ao pivô da relativa, que ocupa uma posição A (argumental) e tem, por isso, independência quanto às suas

\footnotetext{
${ }^{10}$ Delin (1990, p. 85), baseando-se em van der Sandt (1988), afirma que "the presuposition serves the function in discourse of communicating to the hearer that a propositional ANTECEDENT needs to be found or constructed for the presuposed proposition".

${ }^{11} \mathrm{O}$ movimento de constituintes para posições argumentais, isto é, posições em que o constituinte movido recebe papel temático, se constitui de um movimento A, por exemplo, o sujeito de uma sentença passiva. O movimento de constituintes para uma posição não-argumental, isto é, uma posição em que o constituinte não recebe papel temático, se constitui de um movimento A-barra, por exemplo, o movimento de elementos-wh em sentenças interrogativas.
}

Work. pap. linguíst., 13(3): 45-61, Florianópolis, out.dez,2012 
propriedades temáticas, casuais e categoriais (RESENES, 2009, p. 28).

Outra característica de uma sentença clivada que a literatura gerativista afirma é que o pitch accent sempre estará no elemento focalizado, isto é, na posição que antecede o que. Como afirma Franco, as clivadas "são vistas como um tipo relacionado a estratégias sintáticas que o falante utiliza para destacar um elemento prosodicamente sobressalente na sentença" (FRANCO, 2007, p. 33). Essa afirmação é confirmada por estudos de testes induzidos ou de leitura. Araújo, em seu experimento de teste de leitura, menciona que há semelhanças na F0 das sentenças clivadas e pseudo-clivadas, entre elas: "uma parte inicial com acentos tonais mais altos, sobre o foco, seguida por uma rápida descida, sobre o constituinte que inicia o $\mathrm{CP}$ medial que há nessas sentenças, e um final também em tons baixos""12 (ARAÚJO, 2010, p. 110) (grifo nosso).

Assim como a sentença clivada, uma pseudo-clivada também é designada para focalizar. Segundo a abordagem gerativa, a estrutura de uma pseudo-clivada é: sentença wh + ser + XP, por exemplo, [CP [Quemi [SC ti faturou o prêmio[IP foi [DP o Fernandoi]]]]. O XP é a parte não-pressuposta, ou seja, o foco, e a parte pressuposta é a sentença wh. Há outros dois tipos de sentenças pseudo-clivadas: a extraposta e a invertida. A estrutura de uma extraposta é: ser + XP + sentença wh, por exemplo, [IP é [DP a Bruna ${ }_{i}\left[\mathrm{CP}\right.$ quem [ $\mathrm{sc}_{\mathrm{i}}$ faturou o prêmio]]]]. A estrutura de uma pseudo-clivada invertida é: XP + ser + sentença wh, por exemplo, [DP a Marianai [IP é [CP quemi [sc $_{\mathrm{i}}$ faturou o prêmio]]]]. Resenes afirma que a pseudo-clivada invertida é "designada exclusivamente para o foco contrastivo" (RESENES, 2009, p. 55). Há dois tipos de leituras semânticas das pseudo-clivadas, uma especificacional e outra predicacional. Considerando o exemplo de Resenes $\left(2009\right.$, p. 56) ${ }^{13}$ :

(6) O que o João é é importante.

Resenes (2009) explica que o adjetivo 'importante', na leitura especificacional da sentença acima, é um atributo de 'João', predicando sobre o elemento wh 'o que'. Uma paráfrase dessa leitura seria: 'O João é importante'. O adjetivo 'importante', na leitura predicacional', predica sobre toda a sentença wh 'O que o João é'. Uma paráfrase para essa leitura seria: 'O João é alguma coisa e ser essa coisa é importante'. Contudo, a literatura gerativista afirma que só a sentença com leitura especificacional pode ser considerada uma pseudo-clivada, visto que é a única que "apresenta compatibilidade de traços semânticos entre a expressão wh e o XP que está depois da cópula (o foco)" (RESENES, 2009, p. 72).

Outros tipos de construções clivadas são mencionados na literatura, por exemplo, pseudo-clivada reduzida, clivada sem cópula, clivada com dupla cópula, ou ainda com diferentes nomenclaturas, como, sentença copular pseudo-clivada, sentença não-copular pseudo-clivada. Contudo, alguns autores não consideram algumas dessas sentenças como construções clivadas.

\footnotetext{
${ }^{12}$ Em um experimento realizado com gravação de fala espontânea, Stein (2005), investigando o foco contrastivo, chega à interessante conclusão de que "a proeminência prosódica não é marca necessária de foco". Se confirmada essa hipótese por mais pesquisadores, será necessário repensar os estudos sobre a relação foco/pitch e, consequentemente, a relação foco/clivadas, uma vez que o pitch não marcaria foco em todos os casos nessas sentenças.

${ }^{13}$ Exemplo (4) no original.
}

Work. pap. linguíst., 13(3): 45-61, Florianópolis, out.dez,2012 
Neste trabalho, serão consideradas uma clivada e uma pseudo-clivada prototípicas aquelas que são descritas na literatura gerativista, isto é, na forma em que elas são definidas por essa literatura. Contudo, faz-se uma ressalva em relação à pressuposição nos exemplos mencionados na literatura gerativista e nos exemplos dos textos pesquisados para esta pesquisa. Nos textos do corpus utilizado para este trabalho, a pressuposição deve ser construída pragmaticamente, e não por meio de resoluções algorítmicas extraídas de contextos de pergunta/resposta. Por isso, nas ocorrências encontradas no corpus, o foco de identificação exaustiva pode não apresentar uma referência definida, ao contrário dos exemplos gerativistas, em que o foco tem sempre uma referência definida ${ }^{14}$. Para mais informações, cf. nota 14 .

\section{METODOLOGIA E ANÁLISE DOS DADOS}

\subsection{O corpus}

O corpus utilizado neste trabalho foi o C-ORAL-BRASIL (RASO; MELLO, 2012). Esse corpus é uma ramificação de um projeto maior chamado C-ORAL-ROM (CRESTI; MONEGLIA, 2005). O C-ORAL-ROM reúne corpora de fala espontânea das principais línguas românicas da Europa, a saber, espanhol, francês, italiano e português europeu. Em relação às gravações, o projeto leva em consideração o registro linguístico (formal ou informal), o contexto de enunciação (familiar/privado ou público), o número de falantes (monólogos, diálogos e conversações), as características dos falantes (idade, sexo, nível de instrução, profissão e naturalidade) e também a variação diafásica. O C-ORAL-BRASIL segue os moldes do C-ORAL-ROM, que é arquitetado segundo a Teoria da Língua em Ato (CRESTI, 2000).

De acordo com a Teoria da Língua em Ato, o enunciado é a menor unidade linguística possível de ser interpretada pragmaticamente. Os enunciados podem ser segmentados a partir de quebras prosódicas percebidas como terminais. As quebras prosódicas representam as unidades tonais no nível acústico. Cada quebra prosódica, tanto terminal quanto não-terminal, corresponde a uma unidade informacional, no nível pragmático. Com isso, o corpus $^{15}$ é segmentado prosodicamente e etiquetado informacionalmente ${ }^{16}$. Segue um exemplo de um trecho de um texto do C-ORALBRASIL etiquetado informacionalmente:

(7) Texto: bfamd104

*KAT: $[11]$ pois é $/ /=\mathrm{COM}=\$[12]$ depois que a siora fez aquela $/=\mathrm{SCA}=$ hidratação com aloe ele ficou assim $/ /=\mathrm{COM}=\$[13]$ espetado pos lados $/ /=\mathrm{COM}=\$[14]$ antes de passar aquele creme ele nũ tava assim $/=\mathrm{COM}=$ espetado pos lados não $/ /=\mathrm{APC}=\$$

A sigla bfamdl04 significa: corpus 'Brasil', contexto 'familiar', número de falantes 'diálogo' e 04, o número do texto. Logo abaixo, KAT representa as iniciais no nome do falante, [11] é número do enunciado no texto. As barras duplas marcam uma

\footnotetext{
${ }^{14}$ Ressalta-se que a construção clivada apresenta certa estrutura considerada prototípica. Essa estrutura foi tomada do modelo da teoria gerativa para este trabalho, contudo, conforme será mostrado na seção 3.3, há formas diferentes dessas construções ocorrem na língua oral espontânea. As variadas formas dessas construções só são possíveis de ser identificadas através da pesquisa com corpus de fala.

${ }^{15}$ No C-ORAL-BRASIL, somente o minicorpus - uma amostra do corpus que contém as gravações com melhor qualidade de áudio - é etiquetado informacionalmente.

${ }^{16}$ Para explicação de cada unidade informacional no corpus, cf. Rocha (2010).
}

Work. pap. linguíst., 13(3): 45-61, Florianópolis, out.dez,2012 
quebra prosódica percebida como terminal e a barra simples marca uma quebra prosódica percebida como não-terminal. As siglas COM, SCA e APC se referem, respectivamente, às unidades informacionais de comentário, escansão e apêndice de comentário. A parte informal do C-ORAL-BRASIL possui 139 textos, sendo 105 do contexto familiar e 34 do contexto público. A parte formal está em construção.

\subsection{Metodologia}

Inicialmente, buscamos manualmente nos textos transcritos do corpus estruturas sintáticas possíveis candidatas a ser construções clivadas. Em seguida, listamos todos os enunciados em que apareciam essas estruturas e checamos, por meio do contexto em que foram enunciadas e do arquivo de áudio, se seriam construções clivadas. A estrutura deveria ter um item focalizado que expressasse exaustividade. A princípio, várias estruturas poderiam ser consideradas clivadas. Contudo, há que analisar o contexto, a prosódia e verificar também o foco nessas estruturas para se chegar a uma conclusão. A F0 dos enunciados foi checada através do software WinPitchW7 (MARTIN, 2011). Foram excluídas sentenças do tipo mostrada no enunciado [115] em (8):

(8) Texto: bfammn35

*JMA: [113] ah / Gustavo //\$

*JMA: [114] aí / \&fic [/1] \&fi [/1] me pôs de castigo / eu nũ podia sair de casa pra nada / nũ podia encontrar com Leandro / só por telefone / que eu conversava com Leandro //\$ *JMA: [115] é claro que a gente dava umas escapulida / né $/ / \$$

Apesar de a sentença do enunciado [115] do exemplo acima apresentar a estrutura de uma sentença clivada, ela não pode ser uma clivada porque não há foco de identificação. Além da expressão "é claro que" possuir um caráter modal, que poderia ter como um par correspondente o advérbio "claramente" Nota-se, ainda, que a curva da F0 de "é claro" está numa posição mais baixa que o resto da sentença:

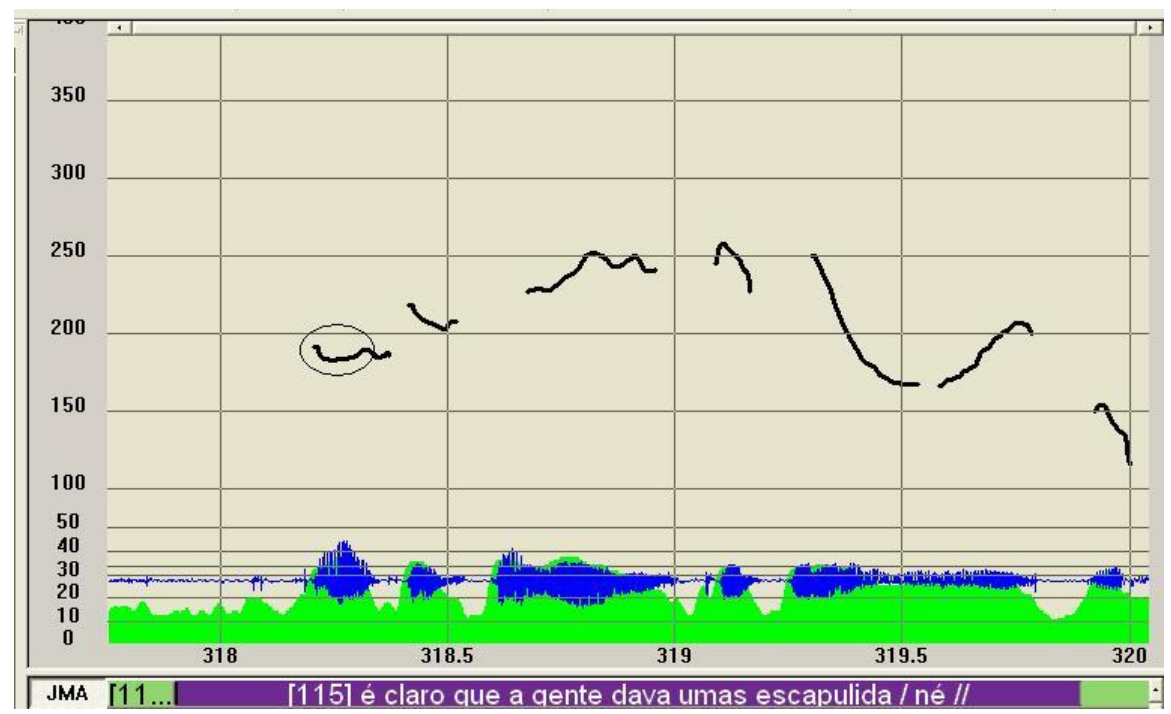

Figura 1 - F0 da sentença "é claro que a gente dava umas escapulida, né?"

Outro tipo de sentença que foi excluída na pesquisa é a do enunciado [144] abaixo, em (9):

(9) Texto: bfammn07

Work. pap. linguíst., 13(3): 45-61, Florianópolis, out.dez,2012 
*NAN: [136] eu tô te ligando / porque me deu muita saudade de você //\$

*NAN: [137] sabe onde que eu tô //\$

*NAN: [138] eu falei / aonde / Edgar //\$

*NAN: [139] eu estou na bica da fazenda //\$

*NAN: [140] e eu desabei a chorar //\$

*NAN: [141] isso me emociona até agora //\$

*NAN: [142] mas eu chorava copiosamente hhh / sabe //\$

*NAN: [143] eu tô na bica aqui da fazenda //\$

*NAN: [144] é um lugar que eu \&go [/1] adorava ir $/ / \$$

*NAN: [145] perto do moinho //\$

*NAN: [146] eu lembrei de você aqui //\$

A sentença do enunciado [144] não pode ser uma clivada porque não há foco de identificação devido à prosódia e ao tipo de informação veiculada nessa posição. $\mathrm{O}$ contexto ajuda a identificar a sentença como uma relativa. Araújo explica que "a entoação é um dos indícios a ser levado em conta para se assumir que as sentenças clivadas não são constituídas por uma relativa" (ARAÚJO, 2010, p. 110) porque "a curva de pitch de uma relativa se apresenta com uma forma mais aplainada que a da sentença clivada" (ARAÚJO, 2010, p.99).

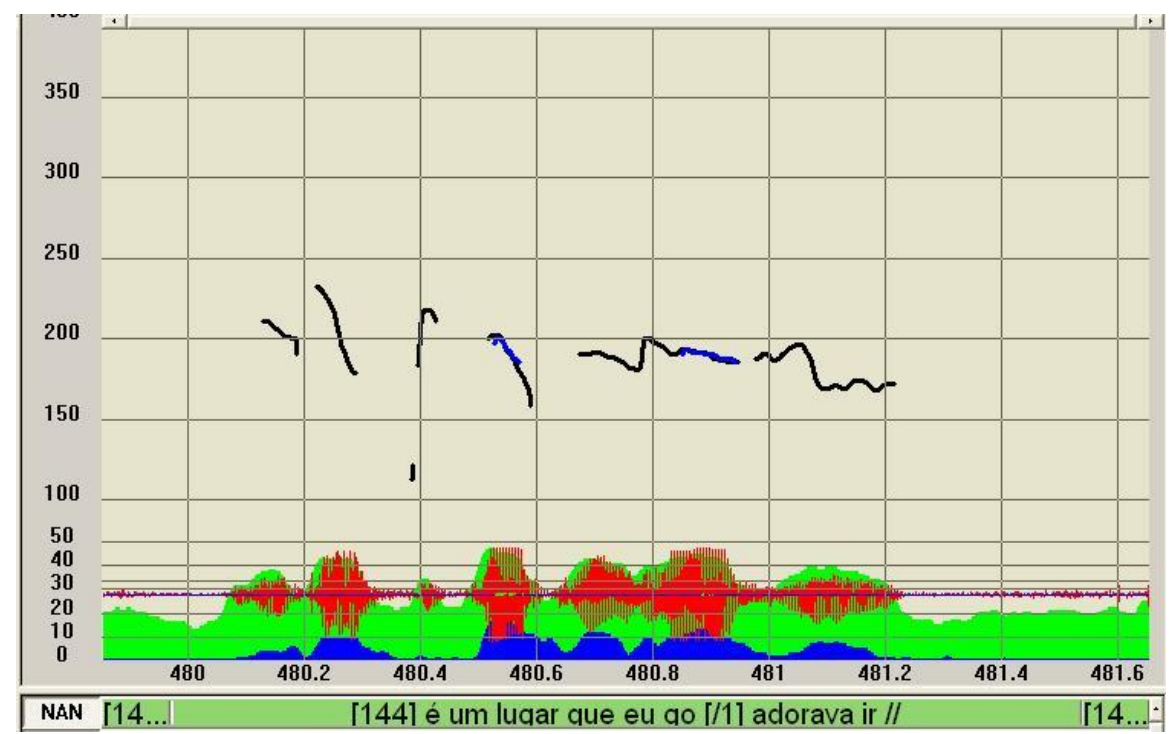

Figura 2 - F0 da sentença "é um lugar que eu go adorava ir"

\subsection{Análise dos dados}

Como citado na seção anterior, os critérios para classificar uma sentença como uma construção clivada neste trabalho foram, sobretudo, a prosódia e o contexto pragmático - para, logo, verificar a natureza do foco. Assim sendo, foram encontradas estruturas prototípicas como em (10) e (11), uma clivada e uma pseudo-clivada, respectivamente:

(10) Texto: bfamdl20

*OSM: [6] cê é um cara / experiente / dando uma mancada dessa //\$

*OSM: [7] falei / uai / eu //\$

*HEL: [8] uhn //\$

*OSM: [9] eu / não //\$ 
*OSM: [10] e foi eu / não //\$

*OSM: [11] foi a Rute que fez \&o [/1] isso aí hhh //\$

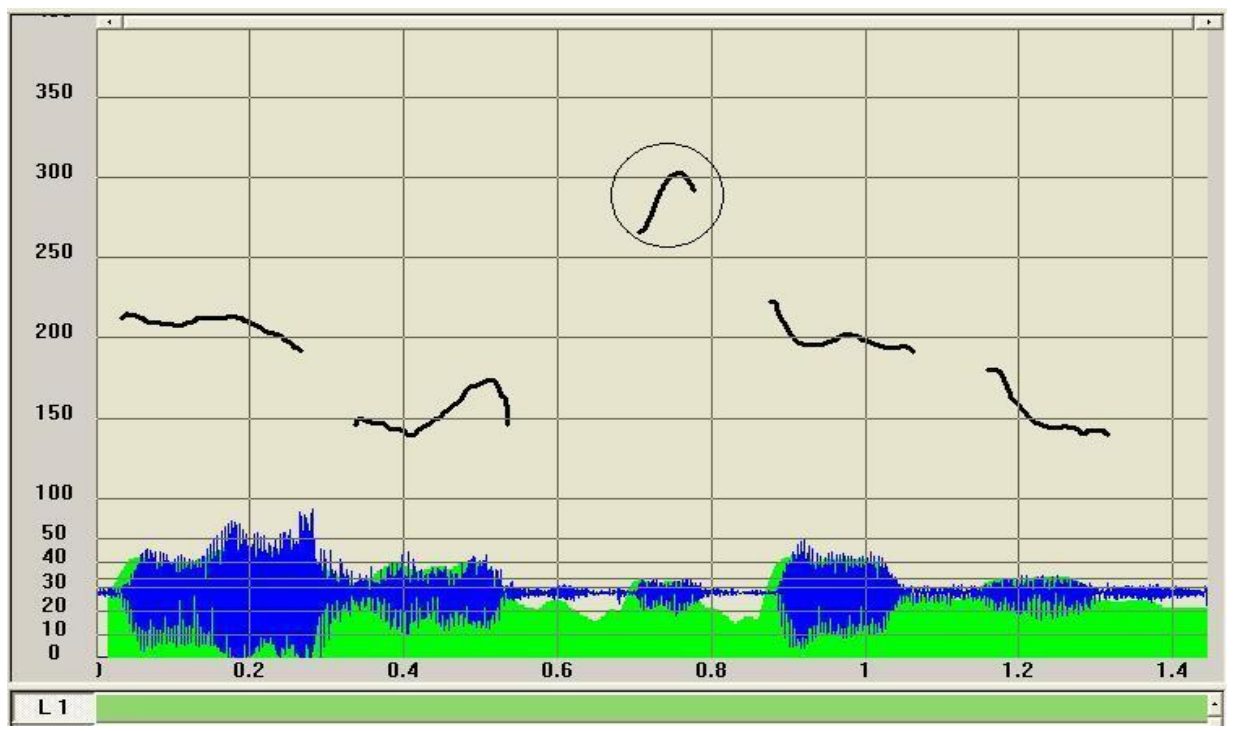

Figura 3 - F0 da sentença "foi a Rute que fez o isso aí"

A sentença clivada está no enunciado [11] do exemplo (10) acima. Mesmo a estrutura sintática sendo prototípica do fenômeno da clivagem, o pitch accent ou o foco prosódico não se encontra na parte não-pressuposta, e sim no elemento 'que', contrariando a proposta recorrente na literatura que diz que o foco prosódico estaria na parte não-pressuposta da sentença (v., p.ex., MODESTO, 2001, p. 108).

(11) Texto: bfamd129

*ELI: [47] você conhece / "perhaps love is like the ocean" nana nana nã nã nã //\$

*ALV: [48] não//\$

*ALV: [49] nũ sei [/2] nũ conheço essa música não //\$

*ELI: [50] é o [/1] o Plácido Domingo / que canta //\$

*ALV: [51] ah //\$

*ALV: [52] morreu //\$

*ELI: [53] não / quem morreu / foi o Luciano Pavarotti hhh //\$

*ALV: [54] ah / é / o [/1] o Pavarotti / é //\$

*ELI: [55] cê tá fazendo confusão dos \&t [/2] dos tenores //\$

Work. pap. linguíst., 13(3): 45-61, Florianópolis, out.dez,2012 


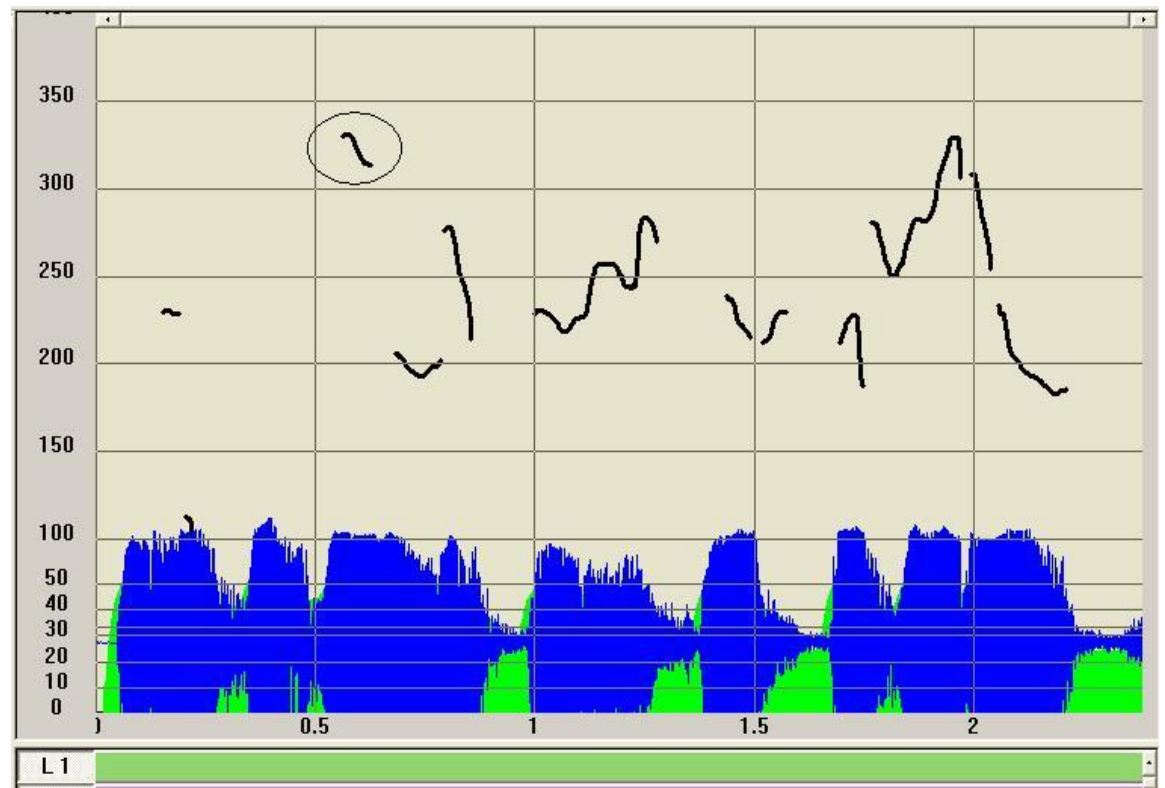

Figura 4 - F0 da sentença "não, quem morreu foi o Luciano Pavarotti"

No enunciado [53] em (11), há um exemplo prototípico de uma sentença pseudoclivada. Assim como na sentença clivada do exemplo (10), o pitch da pseudo-clivada do exemplo (11) não está na parte não-pressuposta. Na pseudo-clivada em (11), o foco prosódico está na primeira sílaba da palavra 'morreu'. A F0 dessas duas sentenças, bem como na de outros exemplos que seguirão, apontaria que os testes induzidos ou de leitura distorceriam os padrões melódicos encontrados na língua oral espontânea. A fala possui um padrão melódico diferente do da leitura, ainda que possa haver alguma coincidência entre os dois, acreditamos que induzir o contexto de enunciação de uma sentença clivada a partir do teste de leitura, poderia evidenciar o padrão melódico que o falante de uma determinada língua tem introspectivamente. A esse respeito, Seara; Figueiredo-Silva (2007a) mencionam que "pode haver diferenças na entoação de sentenças lidas e sentenças ditas (quase) espontaneamente". Esse padrão só seria confirmado ou refutado a partir de dados reais de fala espontânea. $\mathrm{O}$ foco prosódico ou o pitch accent poderia ser atribuído a qualquer parte da sentença, e não só ao foco de identificação ou à parte não-pressuposta.

Também foram encontradas estruturas não-prototípicas, por exemplo, clivadas sem cópula, como em (12). O pitch accent, nesse exemplo, se encontra na primeira sílaba da palavra 'falou'.

(12) Texto: bfamcv05

*CEL: [198] vê aí / saiu / sô //\$

*JOS: [199] saiu //\$

*JOS: [200] saiu //\$

*MAR: [201] olha aqui / <sacanagem mesmo $>/ / \$$

*CAR: [202] <saiu mesmo> //\$

*CEL: [203] <saiu $>/ / \$$

*JOS: [204] o Celsinho que falou / uai //\$

*CEL: [205] saiu / sô / tava lá perto do muro //\$ 


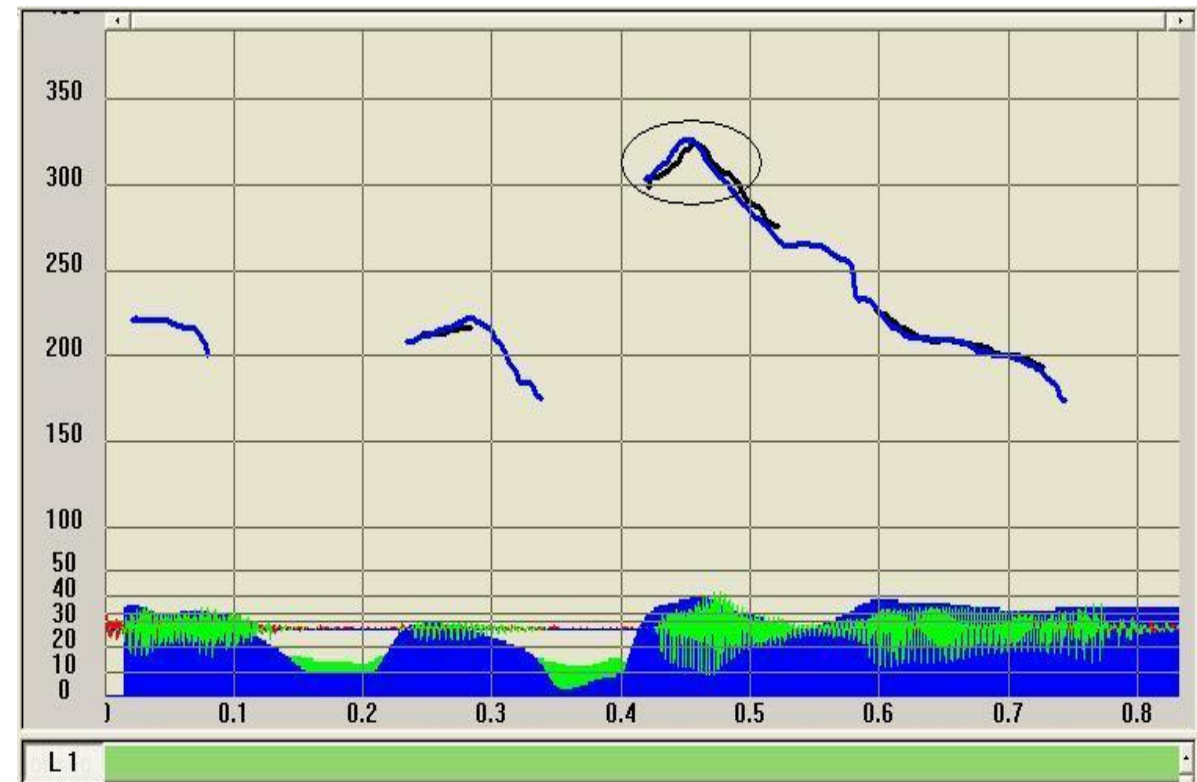

Figura 5 - F0 da sentença "o Celsinho que falou, uai"

Um tipo não encontrado na literatura, que ocorreu no corpus pesquisado foi uma sentença clivada com entonação de pergunta, isto é, uma interrogativa. Nos exemplos (13) e (14) abaixo aparece uma clivada desse tipo com realização da cópula e outra sem realização, respectivamente:

(13) Texto: bpubd107

*COA: [212] porque ela que me deu a blusa / viu //\$

*JAD: [213] com licença //\$

*JAD: [214] portuguesa e à moda //\$

*JAD: [215] foi a siora que pediu à moda / né // \$

*JAD: [216] puxa aí pra mim por favor / que [/1] porque já tá muito quente // \$

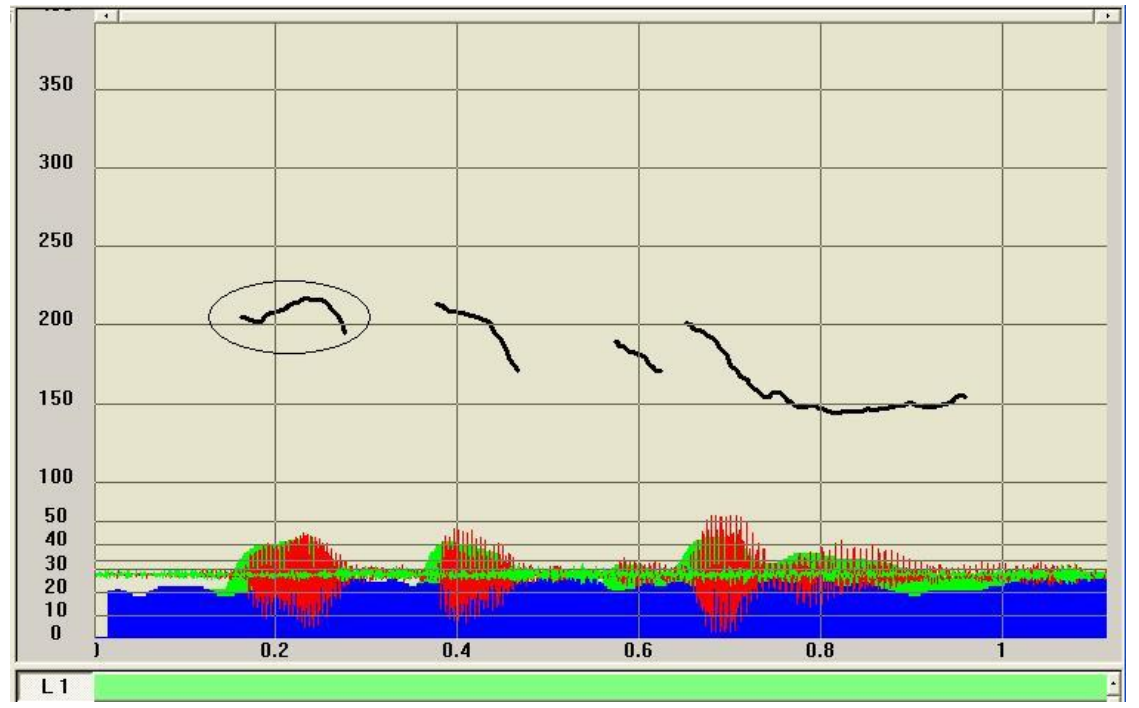

Figura 6 - F0 da sentença “foi a siora que pediu à moda, né?"

(14) Texto: bfamcv03

*CEL: [128] ele vai é rolar //\$

*CEL: [129] olha p' cê ver / vai matar ainda //\$

*CEL: [130] cê vê / voltando aqui o'//\$

Work. pap. linguíst., 13(3): 45-61, Florianópolis, out.dez,2012 
*CEL: [131] <a' lá> / como é que eu pus atrás das outra //\$

*CEL: [132] agora e' descola o nosso jogo lá / cabamo o nosso jogo uai //\$

*CAR: [133] eu que jogo depois dele //\$

*CEL: [134] é //\$

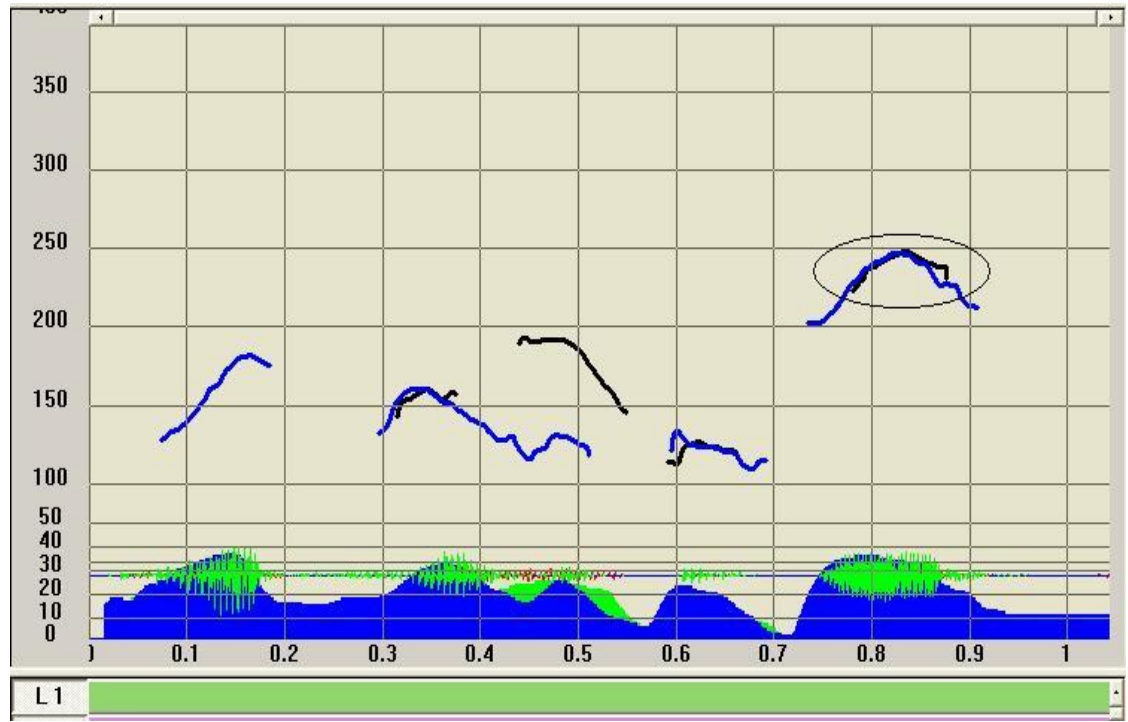

Figura 7 - F0 da sentença “eu que jogo depois dele?"

O pitch accent da sentença do exemplo 13 está na cópula 'foi' e o do exemplo 14 na palavra 'dele'.

Houve casos com a alternância fui/foi nas sentenças clivadas, no exemplo (15) abaixo. Nesse exemplo, o pitch accent está na parte não-pressuposta, sendo um exemplo a favor da hipótese da literatura gerativa.

(15) Texto: bfamcv05

*CAR: [429] pode ir / Zé //\$

*CAR: [430] pode / Zé //\$

*MAR: [431] sua //\$

*CAR: [432] aqui / Zé //\$

*JOS: [433] é nossa //\$

*MAR: [434] ah / aqui não // \$

*CEL: [435] briga não / sô // \$

*JOS: [436] dá / de novo //\$

*CAR: [437] como / sô //\$

*CEL: [438] nossa //\$

*MAR: [439] deles / é deles //\$

*MAR: [440] fui eu que / joguei pra fora $/ / \$$

*CEL: [441] vai lá / sô //\$

*JOS: [442] hhh hhh\$

Work. pap. linguíst., 13(3): 45-61, Florianópolis, out.dez,2012 


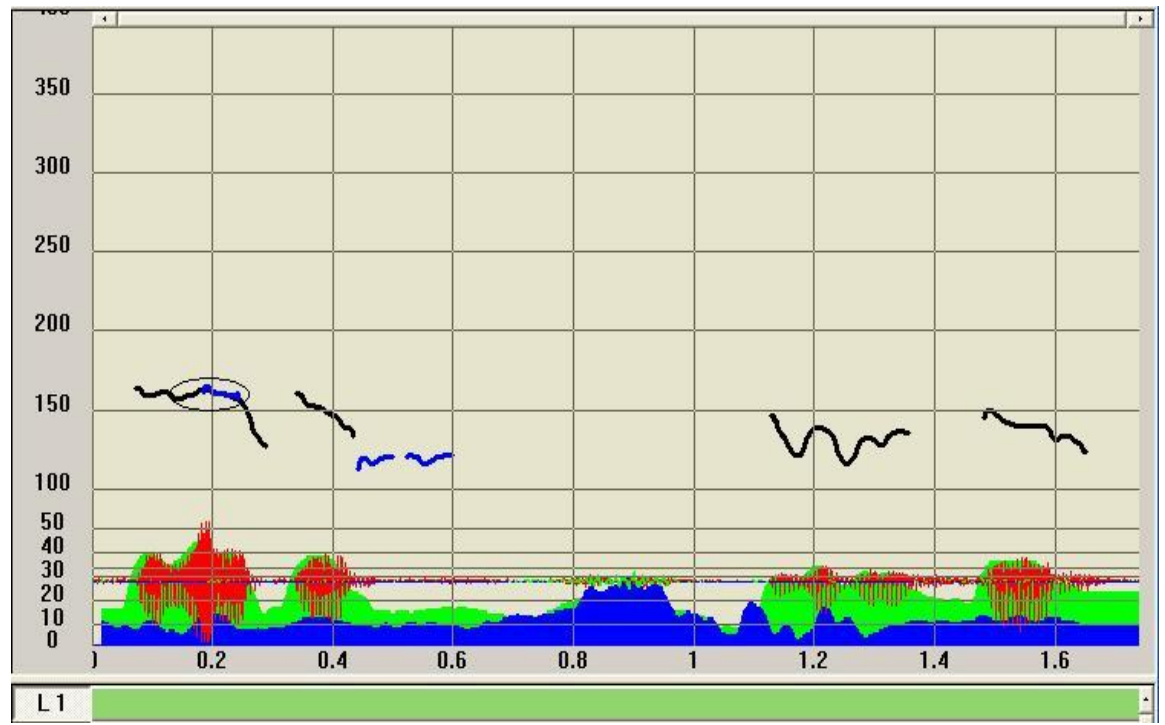

Figura 8 - F0 da sentença "fui eu que joguei pra fora"

Também se encontra no corpus, a ocorrência de uma pseudo-clivada sem cópula, como mostrado em (16). O pitch accent está no elemento wh 'quem'.

(16) Texto: bfamcv02

*TER: [198] <o povo do Zé> Carlos tá querendo ganhar / tadim // \$

*RUT: [199] <só quero $>$ +\$

*TER: [200] ninguém tem $<$ nada $>/ / \$$

*RUT: $[201]<$ hein / Tê $>/ / \$$

*RUT: [202] porque lá em casa / cê sabe / presente da minha família / quem compra só eu / né / minha fillha //\$

*RUT: [203] <porque da família dele / é ele que compra / né> //\$

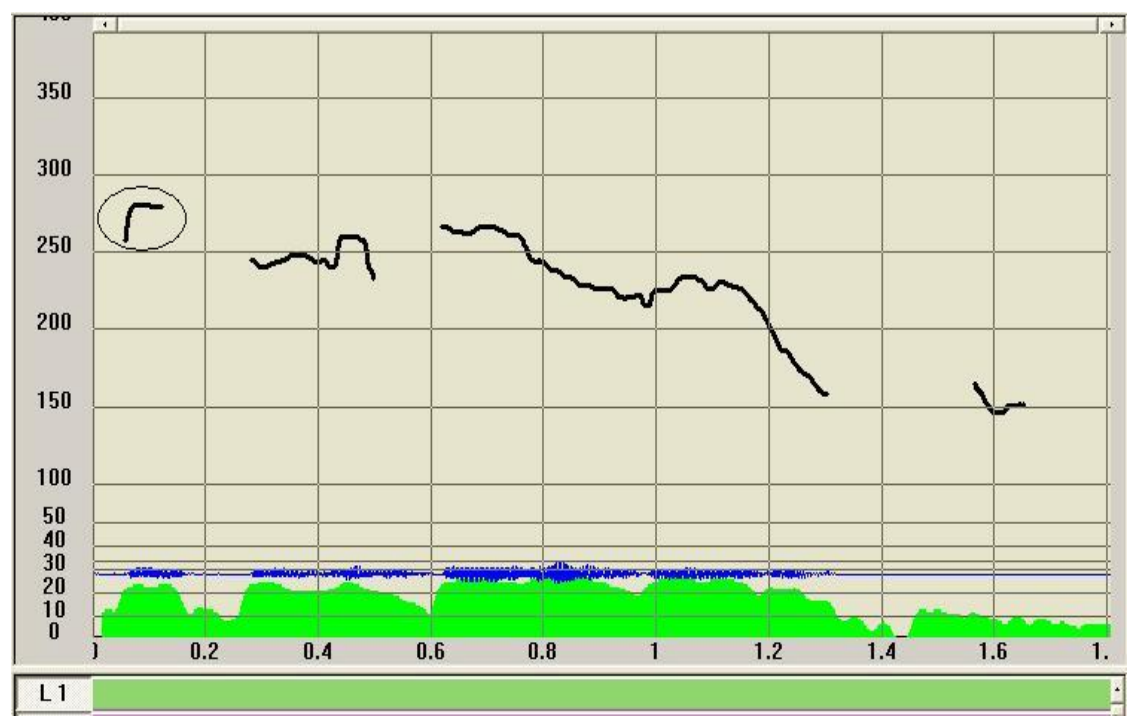

Figura 9 - F0 da sentença "quem compra só eu"

Abaixo, mostramos diferentes tabelas com a quantificação dos dados encontrados na pesquisa ${ }^{17}$.

\footnotetext{
${ }^{17}$ A quantificação dos dados mostrada nas tabelas 1-3 diz respeito à distribuição das construções clivadas encontradas no corpus C-ORAL-BRASIL. Esse corpus é arquitetado seguindo certos parâmetros que
}

Work. pap. linguíst., 13(3): 45-61, Florianópolis, out.dez,2012 


\begin{tabular}{|l|l|l|}
\hline bfamcv & 57 & $37,50 \%$ \\
\hline bfamdl & 50 & $32,90 \%$ \\
\hline bfammn & 20 & $13,15 \%$ \\
\hline bpubcv & 9 & $5,93 \%$ \\
\hline bpubdl & 13 & $8,55 \%$ \\
\hline bpubmn & 3 & $1,97 \%$ \\
\hline Total & 152 & $100 \%$ \\
\hline
\end{tabular}

Tabela 1 - Construções clivadas no corpus C-ORAL-BRASIL segundo o tipo de texto

\begin{tabular}{|l|l|l|}
\hline Familiar/Privado & 127 & $83,5 \%$ \\
\hline Público & 25 & $16,5 \%$ \\
\hline \multicolumn{1}{|c|}{ Total } & 152 & $100 \%$ \\
\hline
\end{tabular}

Tabela 2 - Construções clivadas no corpus C-ORAL-BRASIL segundo contexto de enunciação

\begin{tabular}{|l|l|l|}
\hline Conversação & 66 & $43,42 \%$ \\
\hline Diálogo & 63 & $41,45 \%$ \\
\hline Monólogo & 23 & $15,13 \%$ \\
\hline Total & 152 & $100 \%$ \\
\hline
\end{tabular}

Tabela 3 - Construções clivadas no corpus C-ORAL-BRASIL segundo o número de falantes

\begin{tabular}{|c|c|c|}
\hline Clivadas prototípicas & 68 & $44,73 \%$ \\
\hline Clivadas invertidas & 18 & $11,92 \%$ \\
\hline Clivadas com dupla cópula & 5 & $3,28 \%$ \\
\hline $\begin{array}{ll}\text { Clivadas interrogativas } \\
\text { prototípicas }\end{array}$ & 7 & $4,60 \%$ \\
\hline $\begin{array}{l}\text { Clivadas interrogativas } \\
\text { sem cópula }\end{array}$ & 5 & $3,28 \%$ \\
\hline Clivadas sem cópula & 33 & $21,71 \%$ \\
\hline 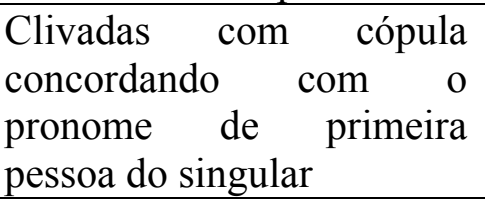 & 1 & $0,65 \%$ \\
\hline $\begin{array}{l}\text { Clivadas invertidas com } \\
\text { cópula concordando com o } \\
\text { pronome de primeira } \\
\text { pessoa do singular }\end{array}$ & 1 & $0,65 \%$ \\
\hline $\begin{array}{l}\text { Pseudo-clivadas } \\
\text { prototípicas }\end{array}$ & 11 & $7,23 \%$ \\
\hline Pseudo-clivadas & 1 & $0,65 \%$ \\
\hline
\end{tabular}

privilegiam a variação diafásica. Entretanto, este trabalho não tem por objetivo fazer uma análise sociolinguística dessas construções, por conseguinte, a quantificação dos dados das tabelas 1-3 diz respeito somente à distribuição desses dados no corpus C-ORAL-BRASIL, não se observou a relação variável-variantes das clivadas por tipo de texto/contexto de enunciação/número de falantes.

Work. pap. linguíst., 13(3): 45-61, Florianópolis, out.dez,2012 


\begin{tabular}{|l|l|l|}
\hline cópula & & \\
\hline $\begin{array}{l}\text { Pseudo-clivadas } \\
\text { interrogativas }\end{array}$ & 1 & $0,65 \%$ \\
\hline Pseudo-clivadas sem wh & 1 & $0,65 \%$ \\
\hline Total & 152 & $100 \%$ \\
\hline
\end{tabular}

Tabela 4 - Construções clivadas no corpus C-ORAL-BRASIL segundo a tipologia

As tabelas mostram que o fenômeno da clivagem no corpus C-ORAL-BRASIL ocorre mais no contexto familiar/privado do que no público, contudo deve ser levado em consideração que o número de textos do contexto público é menor. Pela tabela 4 é possível notar que é mais comum a ocorrência do fenômeno da clivagem em conversações e diálogos do que em monólogos. Isso poderia ser explicado pela natureza de exclusividade e contrastividade que as construções clivadas apresentam, sendo mais comum um falante contrastar ou realçar o que quer dizer para o outro, do que o falante contrastar a seu próprio discurso.

\section{CONSIDERAÇÕES FINAIS}

A partir dos exemplos citados neste artigo, nota-se que o fenômeno da clivagem vai além dos exemplos prototípicos. A construção clivada pode ocorrer na língua espontânea com todos ou sem alguns dos constituintes da sua forma prototípica. A pesquisa com esse tipo de corpus justamente revela essas formas. Araújo (2010, p. 114) explica que "sentenças clivadas e pseudo-clivadas são construções em que, ao mesmo tempo, a informação sintática e a informação prosódica de foco se unem para expressar a estrutura informacional do enunciado". $\mathrm{Na}$ fala espontânea, tanto a informação sintática, quanto a informação prosódica pode sofrer alguma modificação. Contudo, a estrutura informacional não perde seu caráter focalizador. A relação não-prototípica do pitch accent das clivadas mostrado nos exemplos (10-14) e (16) se deve a que "na fala espontânea, os informantes escolhem de forma mais livre os tipos de eventos tonais do que na leitura" (SEARA; FIGUEIREDO-SILVA, 2007b). Não obstante, a relação pitch/foco/clivadas deve ser pesquisada com experimentos de percepção para elucidar questões relacionadas à estrutura prosódica do foco e da sua característica de realce na língua oral espontânea.

\section{REFERÊNCIAS}

ARAÚJO, F. M. A entoação de sentenças clivadas e pseudo-clivadas no português brasileiro. 125f. Dissertação de Mestrado. Universidade Federal de Santa Catarina. Florianópolis, 2010.

BARBOSA, J. Foco e tópico: algumas questões terminológicas. In: RIO-TORTO, G.; FIGUEIREDO, O. M.; SILVA, F. (Eds.). Estudos em homenagem de Mário Vilela. Porto: Faculdade de Letras da U. do Porto, 2005. p. 339-351.

BRAGA, M. L.; BARBOSA, E. de M. Construções clivadas no português do Brasil sob uma abordagem funcionalista. In: Matraga. Rio de Janeiro, v.16, n.24, p.173-196, 2009.

Work. pap. linguíst., 13(3): 45-61, Florianópolis, out.dez,2012 
CRESTI, E. Corpus di italiano parlato. Firenze: Accademia della Crusca, 2000.

CRESTI, E.; MONEGLIA, M. C-ORAL-ROM. Integrated reference corpora for spoken romance languages. Amsterdam/Philadelphia: John Benjamins, 2005.

DELIN, J. L. A multi-level account of cleft constructions in discourse. In: Coling 90: Proceedings of the $13^{\text {th }}$ International Conference on Computational Linguistics, Helsinki, Finland. p.83-88, 1990.

FERNANDES-SVARTMAN, F. R. Entoação e domínios prosódicos em sentenças pseudo-clivadas do português europeu. In: Letras de Hoje. Porto Alegre, v.42, n.3, p.6988, 2007.

FRANCO, P. V. S. Focalização e clivagem: estudo de construções clivadas no português rural de Portugal. 100f. Dissertação de Mestrado. Universidade Federal da Bahia. Salvador, 2007.

GONÇALVES, C. A. Foco e topicalização: delimitação e confronto de estruturas. In: Revista de Estudos da Linguagem. Belo Horizonte. v.7, n.1, p.31-50, 1998.

KISS, K. É. Identificational focus versus informational focus. In: Language, v.74, n.2, p.245-273, 1998

KRUG DE ASSIS, C. Sentenças clivadas e pseudo-clivadas no PB. 2001. 66f. Dissertação de Mestrado. Universidade Federal de Santa Catarina, Florianópolis.

MARTIN, P. WinPitch. Disponível em: <http://www.winpitch.com/>. Acesso em: 28 dez. 2011.

MIOTO, C. Focalização e quantificação. In: Revista Letras. Curitiba, n.61, p.169-189, 2003.

MODESTO, M. As construções clivadas no português do Brasil: relações entre interpretação focal, movimento sintático e prosódia. São Paulo: Himanitas/FFLCH/USP, 2001.

RASO, T.; MELLO, H. C-ORAL-BRASI I: Corpus de referência do português brasileiro falado informal. Belo Horizonte: Editora UFMG, 2012.

RESENES, M. S. Sentenças pseudo-clivadas do português brasileiro. 2009. $143 \mathrm{f}$. Dissertação de Mestrado. Universidade Federal de Santa Catarina. Florianópolis, 2009.

ROCHA, B. M. A unidade informacional de introdutor locutivo no português brasileiro: uma análise baseada em corpus. 2010. 131f. Dissertação de Mestrado. Universidade Federal de Minas Gerais. Belo Horizonte, 2010.

SEARA, I. C.; FIGUEIREDO-SILVA, M. C. Uma nota sobre o padrão entoacional das sentenças VS em português brasileiro. In: Letras de Hoje. Porto Alegre, v.42, n.3, p.114-128, 2007a. 
SEARA, I. C.; FIGUEIREDO-SILVA, M. C. Metodologia para descrição da entoação na interface sintaxe-fonologia. In: Revista Intercâmbio, Volume XVI. São Paulo: LAEL/PUC-SP, ISSN 1806-275X-, 2007b. Disponível em: $<$ http://www.pucsp.br/pos/lael/intercambio/pdf/SEARA_FIGUEIREDO_SILVA_FINA L.pdf>. Acesso em: 29 dez. 2011.

STEIN, C. C. Aspectos da manifestação prosódica em relação com os processos de ativação cognitiva no português. In: Ciências \& Cognição. Vol. 05: 02-18, 2005. Publicado on line em 31 de Julho de 2005. Disponível em: $<$ http://www.cienciasecognicao.org/revista/index.php/cec/article/view/517/287>.

Acesso em: 29 dez. 2011.

VAN DER SANDT, R. A. Context and presupposition. London: Croom Helm, 1988.

ZUBIZARRETA, M. L. Prosody, focus and word order. Cambridge, MA: MIT Press, 1998. 